\title{
Influence of different Processing Parameter on distortion and Residual Stress of Inconel 718 Alloys Fabricated by Selective Laser Melting (SLM)
}

\author{
Yu-shuang Huo ${ }^{a *}$, Chang Hong ${ }^{a, b}$, Huai-xue Li ${ }^{c, d}$, Peng Liu ${ }^{a}$ (]) \\ ${ }^{a}$ Shandong Jianzhu University, School of Materials Science and Engineering, Jinan 250101, China. \\ ${ }^{b}$ University of Science and Technology Beijing, National Center for Materials Service Safety, \\ Beijing, 100083, China. \\ cAVIC Manufacturing Technology Institute, Science and Technology on Power Beam Processes \\ Laboratory, Beijing, 100024, China. \\ ${ }^{d}$ AVIC Manufacturing Technology Institute, Key Laboratory of Aeronautical Technology on additive \\ manufacturing, Beijing, 100024, China.
}

Received: April 27, 2020; Revised: October 05, 2020; Accepted: October 23, 2020

Selective Laser Melting (SLM) is one of additive manufacturing techniques which enable to build a complex structure model layer by layer with 3D CAD software. However, a higher research cost makes it hardly carry out by a traditional methodology, the best way to solve the problem is using simulation software. This paper aims to find an optimal processing parameters combination for a specimen with the smallest distortion and lowest residual stress through Simufact Additive (SA) software. Simulation results under an optimal processing parameters, which led to a smallest value of distortion and residual stress, was the combination of scan power with $300 \mathrm{~W}$, scan speed with $1.3 \mathrm{~m} / \mathrm{s}$, scan interval with one spot diameter $(0.12 \mathrm{~mm})$ and heat treatment holding time with $4 \mathrm{~h}$. In addition, the calculation results provide a novel study method to verify the influence of different processing parameters on Inconel 718 alloys fabricated by SLM.

Keywords: Additive manufacturing, Inconel 718 Ni-based alloys, inherent strain, optimal processing parameter, simufact additive software.

\section{Introduction}

Selective Laser Melting (SLM) is a rapid prototyping technology by utilizing high density energy laser to melt metal powder into a successive layer. With 3D CAD software, more complex structures can be formed easily, and the constructed objects are close to the full density of their bulk metals ${ }^{1}$. Up to now, the SLM techniques in equipment and material preparation have been developed to a certain extent. This technology has been widely used in porous structure, rapid recovery of wear part, medical and dental applications ${ }^{2-5}$.

Due to the rapid melting and cooling rate of the powder in SLM process, it is difficult to study the forming process by traditional research methods. Many researchers prefer to study SLM forming process by numerical simulation. Raghavan et al. ${ }^{6}$ has used a validated heat transfer and fluid flow laser welding model to research the relationships between top surface and subsurface temperatures and solidification parameters in Ti-6Al-4V. The simulation results indicated that the experimental thermography control systems were strengthened by incorporating analysis through mathematical modeling. Ivekovic et al. ${ }^{7}$ has investigated the influence of the SLM processing parameters on the melting and solidification behavior of tungsten and tungsten alloys. The optimal processing conditions resulted in parts with closed porosity was found and microstructural development, crack formation as well

*e-mail: hys6789@126.com as the resulting texture in the finished parts was evaluated. Rudolph and Emmelmann ${ }^{8}$ has studied different statistical based methods for an automated and self-learning calculation for SLM. Amato et al. ${ }^{9}$ has studied the microstructures and mechanical behavior of Inconel 718 fabricated by SLM, and found that the corresponding tensile properties were comparable with wrought Inconel 718 alloy. Azizpour et al. ${ }^{10}$ has utilized a 3D finite element model to simulate the laser beam welding of Ti-6Al-4V sheet and got a good agreement result between simulation and experimentation. To evaluate metallic powders for fabrication of three dimensional models, Abe et al. ${ }^{11}$ has studied the solidifying behavior of metallic powder in selective laser melting process, and found that low vacuum and powder mixture could improve formability in SLM. Qi et al. ${ }^{12}$ has investigated the effects of scanning speed and defocusing distance on the melting mode transition in selective laser melting of A17050 powder and obtained a very well agreement with the experimental result. Leitz et al. ${ }^{13}$ has acquired a deeper insight into the influence of powder characteristics in SLM by numerical simulations. Moser et al. ${ }^{14}$ has developed a discrete element model (DEM) to simulate the effective thermal conductivity of powder beds for selective laser sintering (SLS) applications. Lee et al. ${ }^{15}$ has simulated melt pool shape for multiple layer additive manufacturing.

As mentioned above, it is a fact that the numerical simulation is becoming a popular method on researching 


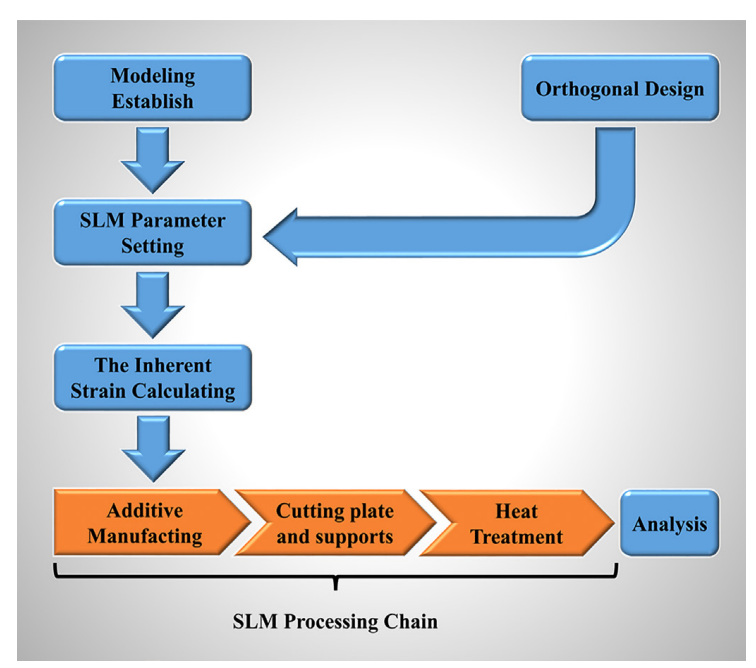

Figure 1. The schematic of working flow.

Table 1. The material properties of Inconel 718 Ni-based alloys.

\begin{tabular}{cccccc}
\hline Parameters & $\begin{array}{c}\text { Density } \\
(\mathrm{Kg} / \mathrm{mm})\end{array}$ & $\begin{array}{c}\text { Poisson } \\
\text { Ratio }\end{array}$ & $\begin{array}{c}\text { Melting } \\
\text { Point } \\
\left({ }^{\circ} \mathrm{C}\right)\end{array}$ & $\begin{array}{c}\text { Solid } \\
\text { Line } \\
\left({ }^{\circ} \mathrm{C}\right)\end{array}$ & $\begin{array}{c}\text { Heat } \\
\text { input } \\
(\mathrm{J} / \mathrm{Kg})\end{array}$ \\
\hline Inconel 718 & $8.15 \times 10^{-6}$ & 0.3 & 1723.15 & 1553 & $2.27 \times 10^{6}$ \\
\hline
\end{tabular}

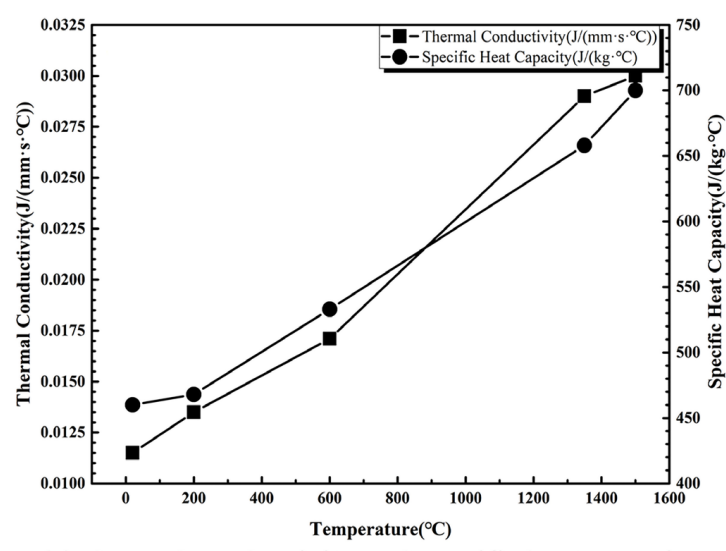

(a) thermal conductivity and specific heat capacity of the SLM process. However, there are few studies on the influence of different process parameters on the forming quality of Inconel 718 Ni-based alloy fabricated by SLM. Aimed to study this issue, the deformation and residual stress were adopted as an indicator of forming quality. And this paper investigated an optimal process parameters combination for a smallest distortion and residual stress with a numerical simulation. This work preset four process parameters, the scan power, scan speed, scan interval and the heat treatment holding time, and each parameter took five levels. The whole working flow of this research is shown in Figure 1.

\section{Processing Parameters Design}

This simulation designed a spot diameter $0.12 \mathrm{~mm}$ laser power to melting the Inconel $718 \mathrm{Ni}$-based alloys powder, and the layer thick is $0.03 \mathrm{~mm}$. The material properties of Inconel $718 \mathrm{Ni}$-based alloys are shown in Table 1 and Figure 2.

In this paper, the four processing parameters were considered as independence, and each one takes five levels (Table 2). It will cost too much times while testing all groups $\left(5^{4}=625\right)$ in this multi-factor and multi-level issue. For decreasing the number of simulating group meanwhile keeping a reliable result, an orthogonal design was adopted ${ }^{16}$, and all the parameter combinations are listed in Table 3.

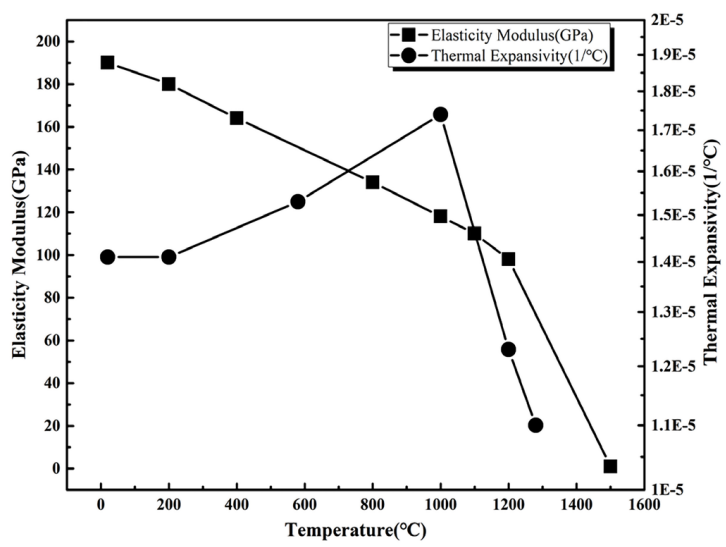

(b) elasticity modulus and thermal expansivity

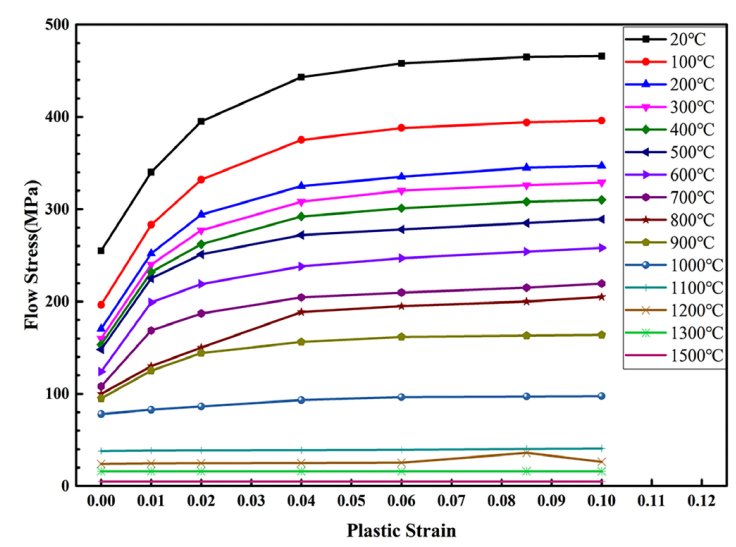

(c) flow stress of varying temperature

Figure 2. Thermal and mechanical properties of Inconel 718 Ni-based alloy: (a) thermal conductivity and specific heat capacity, (b) elasticity modulus and thermal expansivity, (c) flow stress of varying temperature. 
Table 2. The values of different processing parameters.

\begin{tabular}{cccccc}
\hline \multirow{2}{*}{ Parameters } & \multicolumn{5}{c}{ values } \\
\cline { 2 - 6 } & 1 & 2 & 3 & 4 & 5 \\
\hline Scan Power(W) & 300 & 350 & 400 & 450 & 500 \\
\hline Scan Speed/s) & 1000 & 1100 & 1200 & 1300 & 1400 \\
\hline Scan Interval(mm) & 0.03 & 0.06 & 0.09 & 0.12 & 0.15 \\
\hline $\begin{array}{c}\text { Heat Treatment holding } \\
\text { Time (h) }\end{array}$ & 1 & 1.5 & 2 & 3 & 4 \\
\hline
\end{tabular}

Table 3. The parameter combinations of orthogonal Design.

\begin{tabular}{|c|c|c|c|c|}
\hline \multirow[b]{2}{*}{ Number } & \multicolumn{4}{|c|}{ Parameters combination } \\
\hline & $\begin{array}{l}\text { Scan } \\
\text { Power } \\
(\mathrm{W})\end{array}$ & $\begin{array}{c}\text { Scan } \\
\text { Velocity } \\
(\mathrm{m} / \mathrm{s})\end{array}$ & $\begin{array}{c}\text { Scan } \\
\text { Interval } \\
(\mathrm{mm})\end{array}$ & $\begin{array}{l}\text { Heat Treatment } \\
\text { Holding Time } \\
\text { (h) }\end{array}$ \\
\hline $1 \#$ & 300 & 1000 & 0.03 & 1 \\
\hline 2\# & 300 & 1100 & 0.06 & 1.5 \\
\hline $3 \#$ & 300 & 1200 & 0.09 & 2 \\
\hline $4 \#$ & 300 & 1300 & 0.12 & 3 \\
\hline $5 \#$ & 300 & 1400 & 0.15 & 4 \\
\hline $6 \#$ & 350 & 1000 & 0.06 & 2 \\
\hline $7 \#$ & 350 & 1100 & 0.09 & 3 \\
\hline $8 \#$ & 350 & 1200 & 0.12 & 4 \\
\hline 9\# & 350 & 1300 & 0.15 & 1 \\
\hline $10 \#$ & 350 & 1400 & 0.03 & 1.5 \\
\hline $11 \#$ & 400 & 1000 & 0.09 & 4 \\
\hline $12 \#$ & 400 & 1100 & 0.12 & 1 \\
\hline $13 \#$ & 400 & 1200 & 0.15 & 1.5 \\
\hline $14 \#$ & 400 & 1300 & 0.03 & 2 \\
\hline $15 \#$ & 400 & 1400 & 0.06 & 3 \\
\hline $16 \#$ & 450 & 1000 & 0.12 & 1.5 \\
\hline $17 \#$ & 450 & 1100 & 0.15 & 2 \\
\hline $18 \#$ & 450 & 1200 & 0.03 & 3 \\
\hline 19\# & 450 & 1300 & 0.06 & 4 \\
\hline $20 \#$ & 450 & 1400 & 0.09 & 1 \\
\hline $21 \#$ & 500 & 1000 & 0.15 & 3 \\
\hline 22\# & 500 & 1100 & 0.03 & 4 \\
\hline 23\# & 500 & 1200 & 0.06 & 1 \\
\hline $24 \#$ & 500 & 1300 & 0.09 & 1.5 \\
\hline $25 \#$ & 500 & 1400 & 0.12 & 2 \\
\hline
\end{tabular}

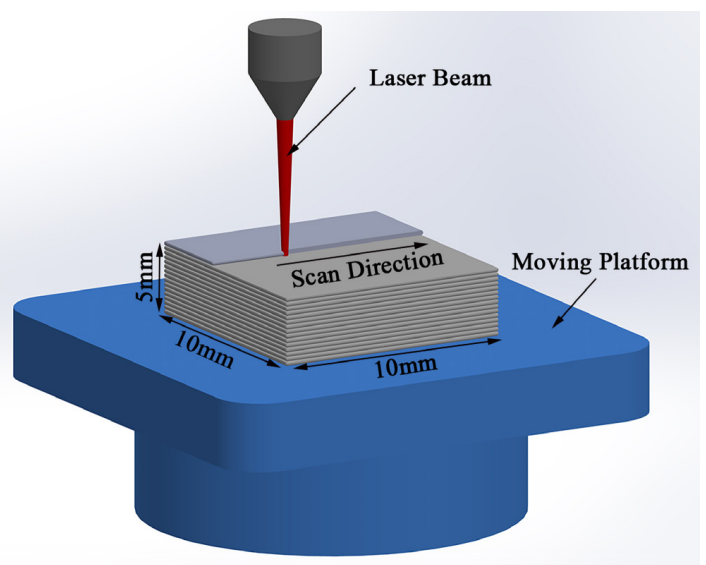

Figure 3. The schematic of building process.
The hexahedron is the simplest and the most widely used space geometry to analyze the deformation and stress field. This paper built a $10 \mathrm{~mm} \times 10 \mathrm{~mm} \times 5 \mathrm{~mm}$ cuboid 3D model by a CAD software (Figure 3 ). After that, the model is imported into Simufact Additive (SA) software to generate mesh, supports and define the material properties. As shown in Figure 3, the metal powder was melted by a high density energy laser beam, and then solidified into a successive layer. Additionally, because of the limitation of the SA software functions, the model in this paper dose not consider some powder properties, such as particle size distribution, morphology or other characteristics.

The inherent stress and inherent strain are firstly put forward by Ueda et al. ${ }^{17}$. The internal existing stress in an object without external stress loading is named the inherent stress. While defining the unstressed and unstrained state as a base state, after a stress cycle, the strains composition in a stressed object is:

$\{\varepsilon\}_{\text {total }}=\{\varepsilon\}_{e l}+\{\varepsilon\}_{p l}+\{\varepsilon\}_{\text {th }}+\{\varepsilon\}_{p h}$

Where, $\{\varepsilon\}_{\text {total }}$ is the total strains, $\{\varepsilon\}_{e l}$ is the elastic strains, $\{\varepsilon\}_{p l}$ is the plastic strains, $\{\varepsilon\}_{t h}$ is the thermal strains and $\{\varepsilon\}_{p h}$ is the phase transformation. While removing from a stress state, the elastic deformation will recovery, the rest strains in Equation 1 are the inherent strains, therefore, the inherent strain $\{\varepsilon\}_{\text {in }}$ is defined:

$\{\varepsilon\}_{i n}=\{\varepsilon\}_{p l}+\{\varepsilon\}_{t h}+\{\varepsilon\}_{p h}$

$\{\sigma\}=[D]\left(\{\varepsilon\}-\{\varepsilon\}_{\text {in }}\right)$

Where, $\{\sigma\}$ is the stress state, $[D]$ is the elasto-plastic stiffness matrix, $\{\varepsilon\}$ is the strain state.

In a thermal-elastic-plastic theory, the temperature field will first be calculated, then the thermal increment is applied to calculate the stress field. During calculating a large model, the time consuming is too much with this theory. When the inherent strain theory is adopted, it only takes a few steps to calculate the deformation and stress field ${ }^{18,19}$.

Firstly, the model is meshed into some voxel elements and all of the voxel elements are treated as the same one in different location or direction; then by inputting the process parameters, such as power, scan speed, scan width, etc., the inherent strain of one element in different direction $\left(\varepsilon_{x}, \varepsilon_{z}, \varepsilon_{z}\right)$ is calculated. Secondly, Add the first layer voxel elements on the base metal, calculate the total distortion by the inherent strain, and then according to Equation 3 calculate the stress state, balance the force field and calculate other properties. Thirdly, add a new layer, correct the orientation (applied an incremental angle) and recalculate the strain field, stress field, force field, etc. It should be notice that each layer has itself scan direction, which corresponds to the scan strategies. In the SA software, a start angle $\alpha_{0}$ and incremental angle $\Delta \alpha$ are defined. The start angleis the angle of orientation with respect to the base plate $\mathrm{x}$ direction. It is applied to the first layer and default value is $0^{\circ}$. The incremental angle is the orientation of the new consecutive printed layers, and default value is $67^{\circ}$. The estimate dialog box and setting of scan strategies are shown in Figure 4.

As shown in Figure 1, the heat treatment is the last step of SLM simulation. After additive manufacture, base plate 
and support removal, the specimen is in high stress state which should be heated to a higher temperature to release the stress. The specimen could not get its best mechanical properties until heat treatment processing finished. The heat treatment curve is shown in Figure 5.

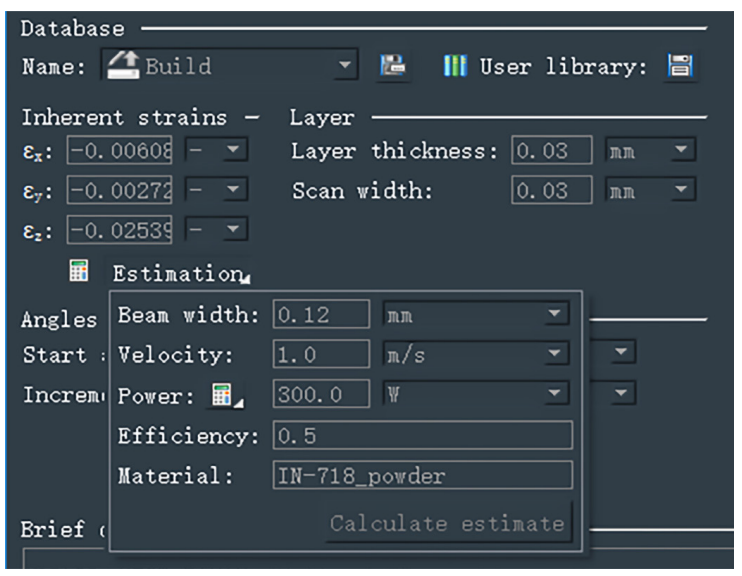

Figure 4. The estimation value of inherent strains.

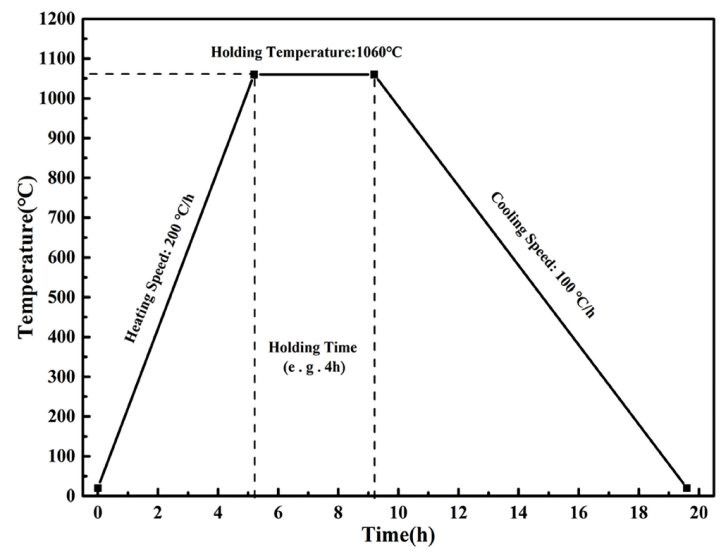

Figure 5. The schematic of heat treatment process curve.

\section{Results and Discussion}

\subsection{Influences of processing parameters on distortion}

In industrial production, SLM is used to form high-precision parts utilizing powder materials. However, the distortion and residual stress are the most two obvious problems. With the high cost of powder, it could not be research by a traditional methodology. The use of simulation software to study the problems generated in the manufacturing process has become a unique method to reduce the costs. The contour map of simulation is shown in Figure 6. After calculating, each group results data were collected together, and then analyzed using orthogonal analysis method. By the orthogonal analysis, the effects of different process parameter on the distortion and residual stress are obtained, as shown in Figure 7 and Figure 8.

According to Figure 7, it is obvious that different parameters have different effect to distortion, and the wave range of diagrams indicates that the holding time of heat treatment is the most effective factor, the others in large to small order is scan power $>$ scan velocity $>$ scan interval. Therefore, it is essential to choose proper heat treatment holding time to achieving minimum distortion. However, it does not mean the other parameter is insignificant, and the main purpose of this work aims to find an optimum parameter combination to obtain the minimum distortion. As shown in Figure 7a, b and c, all the curves have an $\mathrm{S}$ shape. The distortion is increasing with the scan power increasing in Figure 7a. While in Figure 7b, the distortion is decreasing with the increasing scan velocity within limits. Similar to Figure $7 b$, the tendency in Figure $7 \mathrm{c}$ is also first decrease then increase, but the wave range is smaller in the latter.

Different parameters lead to different heat input, and then result in different distortion and stress. The heat input equation $^{6}$ is shown in Equation 4:

$E_{h}=\frac{\eta P L W H}{v W_{i} T_{l}}$

Where, $E_{h}$ is the heat input, $\eta$ is the efficiency, $P$ is the power, $L$ is the length of each layer along the scan direction, $W$ is the width of each layer, $H$ is the total height of the printing

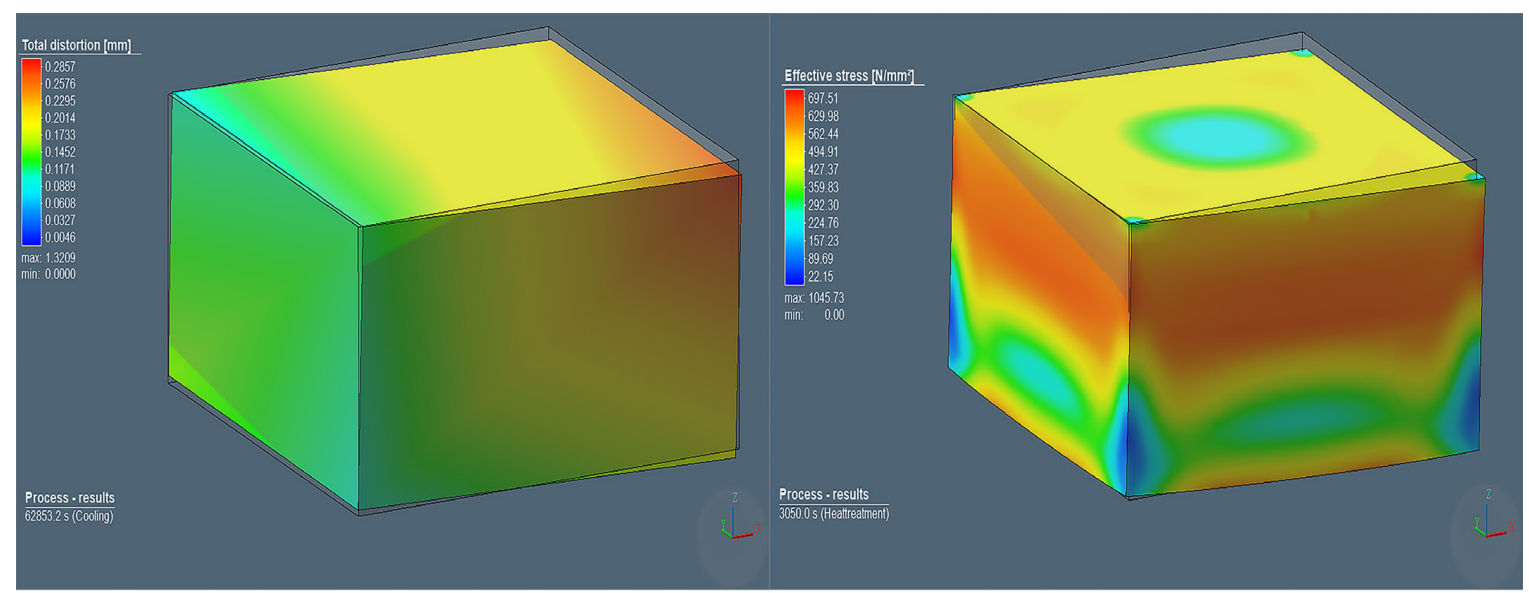

(a) distortion results

(b) effective stress results

Figure 6. The contour map showing simulation results: (a) distortion results, (b) effective stress results. 


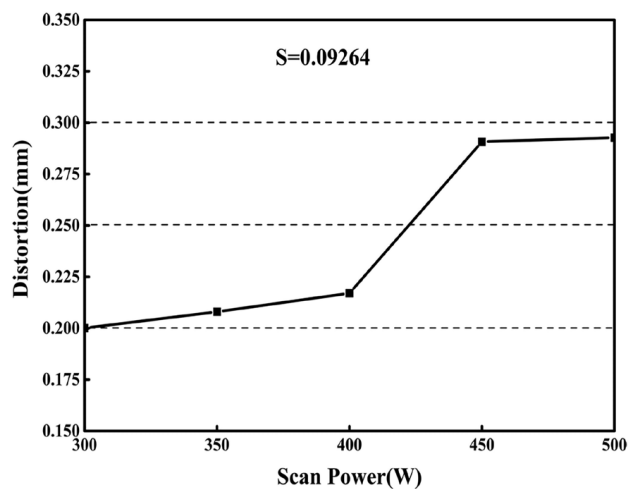

(a) The influence of Scan Power

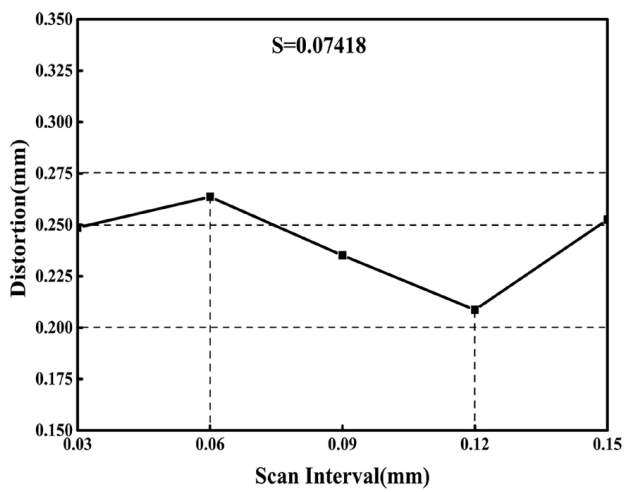

(c) The influence of Scan Interval

Figure 7. The distortion influence of different process parameters.

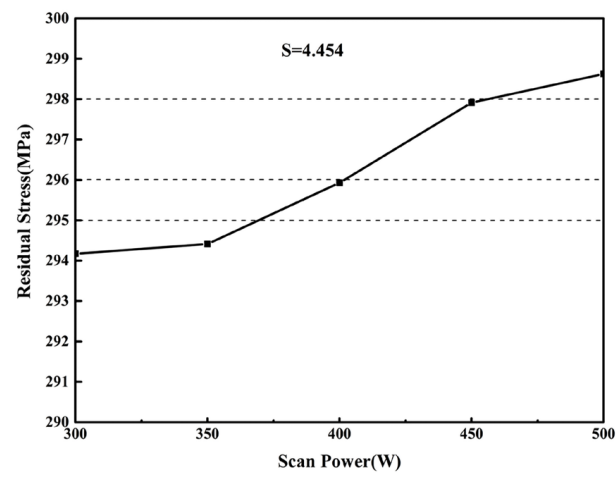

(a) The effect of Scan Power

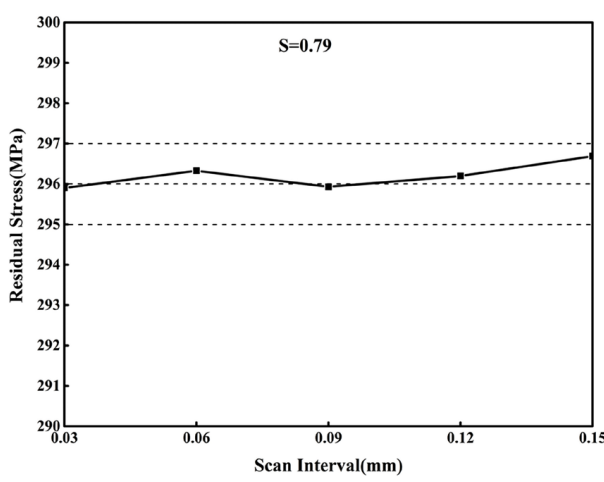

(c) The effect of Scan Interval

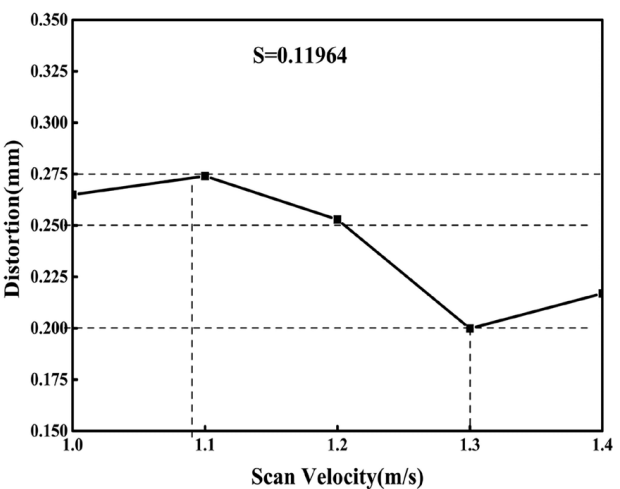

(b) The influence of Scan Velocity

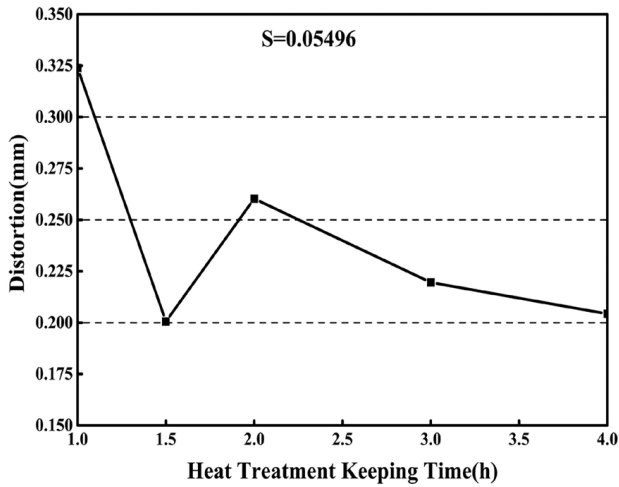

(d) The influence of Heat Treatment Keeping Time

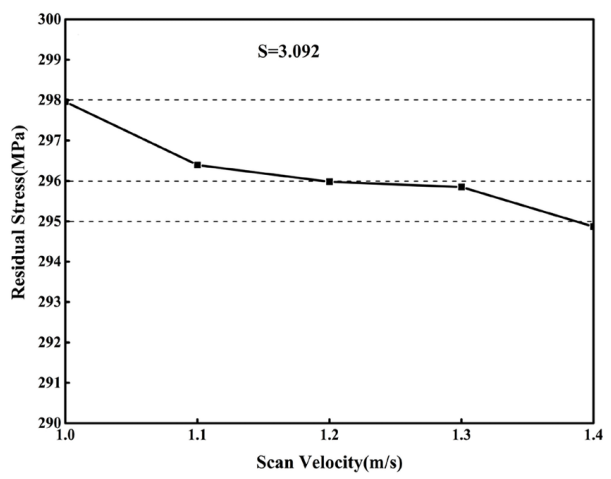

(b) The effect of Scan Velocity

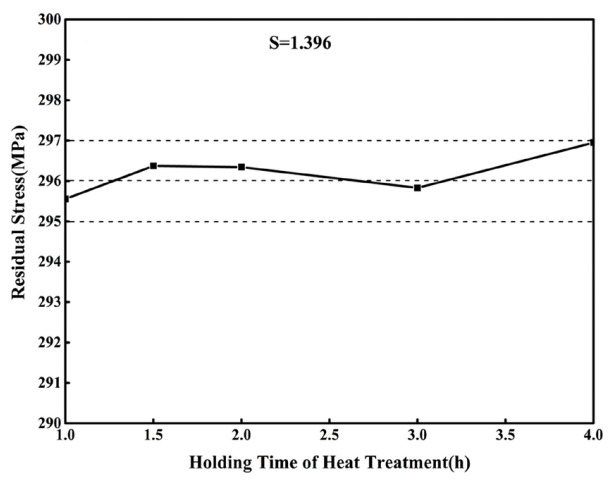

(d) The effect of Heat Treatment Keeping Time

Figure 8. The effect of different parameter to residual stress. 
model and support, $v$ is the scan velocity, $W_{i}$ is the scan interval, $T_{l}$ is the layer thickness.

In Figure 7a, the distortion is lower while the power less than $400 \mathrm{~W}$, and the distortion are increasing with the power increase. When the power is beyond $450 \mathrm{~W}$, the tendency of curve is growing slowly. From Equation 4, it could be seen that a bigger power leads to a larger heat input. For decreasing the distortion during SLM, the $300 \mathrm{~W}$ is the optimal power.

In Figure $7 b$, it could be seen is that the distortion decreases with a growth scan speed, which is consistent with Equation 4. While the scan speed is small, the power stayed time in a certain distance is much longer. Therefore, the distortion is much more obvious for a bigger heat input because of the greater segregation. As a consequence, the distortion decreases with the rising of scan speed. When the speed is much higher (i.e. $1400 \mathrm{~mm} / \mathrm{s}$ ), the distribution of heat flux is uneven, resulting in larger deformation. To obtain the minimum distortion, the $1300 \mathrm{~mm} / \mathrm{s}$ is optimal in this study.

The heat input is inversely proportional to the scan interval, as shown in Equation 4. A small interval that narrows the distribution of heat input in a volume. Therefore, the distortion decreases as the scan interval increases. In Figure 7c, when the scan interval is much bigger, especially greater than the spot diameter $0.12 \mathrm{~mm}$, the heat flux distribution is not uniform, which will lead to large deformation. The optimum scan interval is $0.12 \mathrm{~mm}$.

In Figure 7d, the distortion is decreasing with the heat treatment holding time extension. With the extension of heat treatment holding time, the segregation phase will be transformed into uniform phase. Therefore, a smaller distortion is generating and $1060^{\circ} \mathrm{C}+4 \mathrm{~h}$ is the optimal chosen.

\subsection{Influences of processing parameters on residual stress}

As mentioned before, the larger scan power results in a larger heat input, then generating the high residual stress. From Figure 8a, it can be observed that a lower power will obtain the lower residual stress. Therefore, the optimal scan power is $300 \mathrm{~W}$.

It is similar to the distortion, the residual stress increases with the slowing down of scanning speed. From Figure 8b, when the speed is $1.4 \mathrm{~m} / \mathrm{s}$, the residual stress is lowest. However, compared with $1.3 \mathrm{~m} / \mathrm{s}$, the difference in stress is not much obvious $(\sim 1 \mathrm{MPa})$. Considering the distortion is a minimum value at $1.3 \mathrm{~m} / \mathrm{s}$, the optimal scan speed to obtain the minimum residual stress is $1.3 \mathrm{~m} / \mathrm{s}$.

The influence of scan interval on residual stress is extremely unobvious than other parameters. From Figure 8c, it can be seen that the data wave range is only $0.79 \mathrm{MPa}$. That means the scan interval is not the main factor of influence on residual stress. The optimum scan interval could be $0.12 \mathrm{~mm}$.

Despite carried out the heat treatment process, the residual stress is just released within a limited range. From Figure $8 d$, it could be seen that the minimum residual stress is at $1.0 \mathrm{~h}$, while the value at $3.0 \mathrm{~h}$ is $0.3 \mathrm{MPa}$ higher than $1.0 \mathrm{~h}$. And all the results are above $295 \mathrm{MPa}$ but less than $297 \mathrm{MPa}$, the value fluctuation is about $0.51 \%$ of the minimum value. Thus, it could be found that the residual stress is much less affected by holding time of heat treatment than which by the scan power or by the scan velocity. While comparing the effect of holding time of heat treatment on distortion(the value fluctuation is about $12.5 \%$ of the minimum value, when the holding time of heat treatment time exceeds 3.0 hfrom Figure $7 \mathrm{~d}$ ), the range of the optimal holding time is $4.0 \mathrm{~h}$.

From references ${ }^{20-22}$, it could be learned that a short heating and cooling time during SLM additive manufacturing may lead to a large number of segregation phases generation. The existing of segregation phase is the main factor generating residual stress, and the bigger ratio of segregation phase in the specimen results in a larger residual stress. The heat treatment process will homogenize the segregation. As stated by Liu et al. ${ }^{20}$, when the heat treatment time is long enough, the $\delta$ phase will be generated. Based on this, the effect of different parameter on residual stress could be explained.

\subsection{Calculation results of optimal processing parameters}

Aimed to achieve a smallest distortion or residual stress, this study finally obtained the optimal parameter combinations. The scan power is $300 \mathrm{~W}$, the scan velocity is $1.3 \mathrm{~m} / \mathrm{s}$, the scan interval is one spot diameter $(0.12 \mathrm{~mm})$ and the holding time of heat treatment is $4 \mathrm{~h}$. In order to

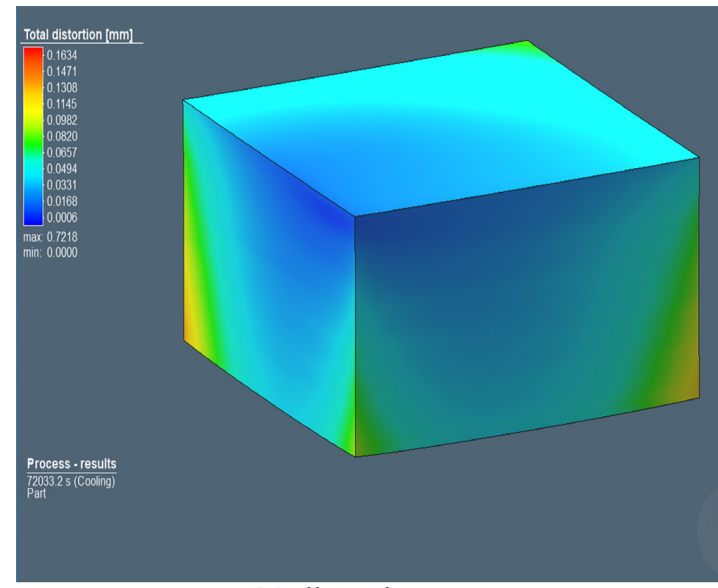

(a) distortion contour

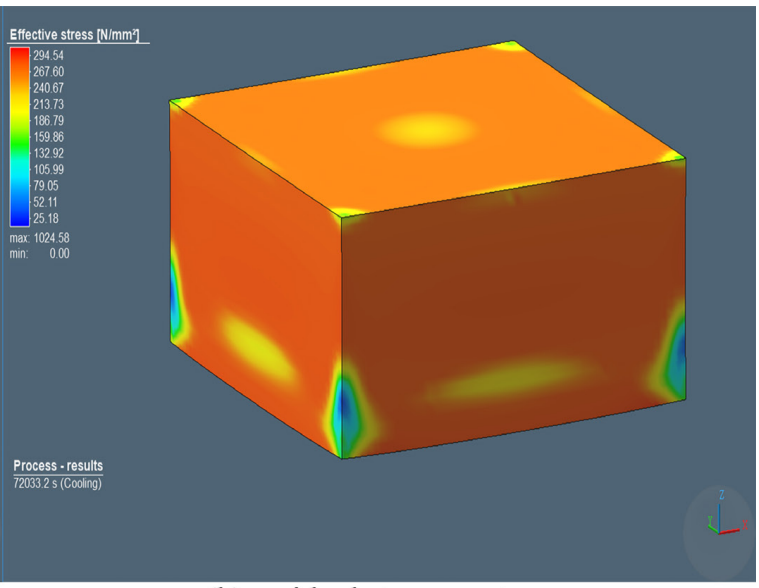

(b) residual stress contour

Figure 9. The simulation results of the optimal parameters: (a) distortion contour, (b) residual stress contour. 
verify the validity of these parameters, a simulation is calculating again. The recalculated results are shown in Figure 9. The max distortion is $0.1634 \mathrm{~mm}$, which are the smallest compared with all the data in Figure 7. The residual stress is $294.54 \mathrm{MPa}$, which is close to the minimum value (294.17MPa) in Figure 8a. Finally, the conclusion could be drawn that using simulation to obtain the optimal parameters combinations is workable and the results can be used as a guide for subsequent experiments.

\section{Conclusions}

In this paper, the relation between processing parameters and fabricating distortions and residual stress were analyzed. The following concluding remarks can be drawn:

1. The holding time of heat treatment has a significant effect on the deformation, and the order of influence of other parameters is scan power $>$ scan velocity $>$ scan interval. All of the influence curve of scan power, scan speed, scan interval on distortion show an $\mathrm{S}$ shape, however, the wave range of scan interval influence curve is smallest. When the scan power is less than $400 \mathrm{~W}$, scan speed is $1.2 \mathrm{~mm} / \mathrm{s} \sim 1.3 \mathrm{~mm} / \mathrm{s}$, scan interval is less than one spot diameter and the holding time of heat treatment is longer than $3 \mathrm{~h}$, the distortion would be smaller.

2. Residual stress is increasing with a growth of scan power, and increasing with a decreasing scan velocity. The optimal range of such two parameters is a less than $400 \mathrm{~W}$ scan power and a scan speed $1.2 \mathrm{~mm} / \mathrm{s} \sim 1.3 \mathrm{~mm} / \mathrm{s}$. The influence of scan interval is not much obvious, and its best range is less than one spot diameter $(0.12 \mathrm{~mm}$ in this study). The optimal range of heat treatment holding time is greater than $3 \mathrm{~h}$. Using this rule determinates a group of parameters is verified that has the smallest distortion and a similar stress value by recalculation.

\section{Acknowledgments}

The authors gratefully acknowledge the support by National Key R\&D Program of China (Grant No. 2017YFB1104002).

\section{References}

1. Buchbinder D, Schleifenbaum H, Heidrich S, Meiners W, Bültmann J. High power selective laser melting (HP SLM) of aluminum parts. Phys Procedia. 2011;12:271-8.

2. Panwisawas C, Perumal B, Ward RM, Turner N, Turner RP, Brooks JW, et al. Keyhole formation and thermal fluid flowinduced porosity during laser fusion welding in titanium alloys: experimental and modelling. Acta Mater. 2017;126:251-63.

3. Yap CY, Chua CK, Dong ZL, Liu ZH, Zhang DQ, Loh LE, et al. Review of selective laser melting: materials and applications. Appl Phys Rev. 2015;2(4):041101.

4. Vilar R, Almeida A. Repair and manufacturing of single crystal Ni-based superalloys components by laser powder deposition: a review. J Laser Appl. 2015;27(S1):17004.
5. Shishkovskii IV, Yadroitsev IA, Smurov IY. Selective laser sintering/melting of nitinol-hydroxyapatite composite for medical applications. Powder Metall Met Ceramics. 2011;50(56):275-83.

6. Raghavan A, Wei HL, Palmer TA, Debroy T. Heat transfer and fluid flow in additive manufacturing. J Laser Appl. 2013;25(5):052006.

7. Ivekovic A, Omidvari N, Vrancken B, Lietaert K, Thijs L, Vanmeensel K, et al. Selective laser melting of tungsten and tungsten alloys. Int J Refract Met Hard Mater. 2018;72:27-32.

8. Rudolph J, Emmelmann C. Self-learning calculation for selective laser melting. Procedia CIRP. 2018;67:185-90.

9. Amato KN, Gaytan SM, Murr LE, Martinez E, Shindo PW, Hernandez J, et al. Microstructures and mechanical behavior of Inconel 718 fabricated by selective laser melting. Acta Mater. 2012;60(5):2229-39.

10. Azizpour M, Ghoreishi M, Khorram A. Numerical simulation of laser beam welding of Ti6Al4V sheet. JCARME. 2015;4:14554.

11. Abe F, Shiomi M, Osakada K. Solidifying behaviour of metallic powder in selective laser melting process. Procedia Eng. 2017;207:1188-93.

12. Qi T, Zhu HH, Zhang H, Yin J, Ke L, Zeng XY. Selective laser melting of Al7050 powder: melting mode transition and comparison of the characteristics between the keyhole and conduction mode. Mater Des. 2017;135:257-66.

13. Leitz KH, Grohs C, Singer P, Tabernig B, Plankensteiner A, Kestler H, et al. Fundamental analysis of the influence of powder characteristics in Selective Laser Melting of molybdenum based on a multi-physical simulation model. Int J Refract Met Hard Mater. 2018;72:1-8.

14. Moser D, Pannala S, Murthy J. Computation of effective thermal conductivity of powders for selective laser sintering simulations. J Heat Transfer. 2016;138(8):082002.

15. Lee Y, Farson DF. Simulation of transport phenomena and melt pool shape for multiple layer additive manufacturing. J Laser Appl. 2016;28(1):012006.

16. Telford JK. A brief introduction to design of experiments. Johns Hopkins APL Tech Dig. 2007;27:224-32.

17. Ueda Y, Murakawa H, Gu S, Okumoto Y, Kamichika R. Simulation of welding deformation for accurate ship assembling (1st Report) in-plane deformation of butt welded plate. J. Soc. Naval Architects of Japan. 1992;171(171):395-404.

18. Boyd SK, Muller R. Smooth surface meshing for automated finite element model generation from 3D image data. J Biomech. 2006;39(7):1287-95

19. Nakacho K, Ogawa N, Ohta T, Nayama M. Inherent-strainbased theory of measurement of three-dimensional residual stress distribution and its application to a welded joint in a reactor vessel. J. Pressure Vessel. 2014;136(3):031401.

20. Liu P, Sun SY, Xu XB, Cao MQ, Hong C, Hu JY. Effect of solid solution + double ageing on microstructure and properties in the layer by layer of the Z-Y interface of Inconel 718 alloys fabricated by SLM. Mater Res. 2018;21(6):e20180395.

21. Kistler NA, Nassar AR, Reutzel EW, Corbin D, Beese AM. Effect of directed energy deposition processing parameters on laser deposited Inconel ${ }^{\circledR}$ 718: Microstructure, fusion zone morphology, and hardness. J Laser Appl. 2017;29(2):022005.

22. Li H, Feng S, Li J, Gong J. Effect of heat treatment on the $\delta$ phase distribution and corrosion resistance of selective laser melting manufactured Inconel 718 superalloy. Mater. Corr. 2018;69(10):1350-4. 